\title{
The Principles and Implementations Strategy by Automobile Industrial Heritage Protection of Shiyan, China
}

\author{
Chuan-chuan Huang ${ }^{1,2}$, Yao-lin Zhou ${ }^{1}$ \\ ${ }^{1}$ School of information management, Wuhan University, Wuhan, China \\ ${ }^{2}$ Shenzhen Polytechnic, Shenzhen, China
}

\begin{abstract}
This paper bases on the demand of automobile industrial heritage protection of China. It analyze the present situation and existing problems of automobile industrial heritage protection in Shiyan. Through to combine with the advanced protection concepts and existing urban basic environment, it puts forward the automobile industrial heritage protection principle, implementation measures and specific strategies.
\end{abstract}

Keywords - Shiyan, Automobile industrial heritage, Protection principle, Implementation strategies

\section{湖北省十堰市汽车工业遗产的保护原则与实施策略}

\author{
黄川川1,2 a 周耀林 ${ }^{1, \mathrm{~b}}$ * \\ 1武汉大学信息管理学院,武汉,湖北,中国 \\ 深圳职业技术学院,深圳,广东,中国
}

摘 要 本文从我国汽车工业遗产保护的需求出发, 通过对十堰市汽车工业遗产保护现状的分析和问题的归纳, 结合先进工业 遗产保护理念和现有城市基础环境, 针对性地提出了十堰市汽车工业遗产保护的基本原则和实施策略。

关键词 十堰市，汽车工业遗产，基本原则，实施策略

\section{1. 引言}

湖北省十堰市被誉为“东方底特律”, 随着东风公司将 轿车和轻卡分设到武汉、襄森及广州发展之后, 十堰市内 大量的汽车工业厂房和工业设备被逐步被闲置和淘汰, 逐 步形成了大量的汽车工业遗存。

随着社会经济发展的不断深化, 在巨大的城市空间发 展需求和土地供给日益短缺的压力下，处于城市中心和近 郊区的汽车工业用地早已成为令人注目的开发对象, 而这 些老旧的汽车工业遗存先后遭遇了“二汽”战略调整、产品 陈旧老化、原有市场衰退等发展问题，而转让土地使用权， 用转让资金安置分流人员、清理债务、转型发展, 似乎成 为这些汽车工业企业唯一的出路, 十堰市汽车工业遗产也
正面临灭顶之灾，“东方底特律”已渐成神话。面对这一严 峻的形势, 根据国际工业遗产保护的发展潮流, 因地制宜 地制定十堰市汽车工业遗产的生产性保护策略和举措, 实 现工业遗产的有效保护和科学利用已显得尤为迫切。

\section{2. 汽车工业遗产保护的主要问题}

\section{1 遗存濒临消失}

自1985年我国加入《保护世界文化和自然遗产公约》 以来, 社会各界对数千年来祖先创造的历史遗存呵护有加, 但面对几十年我们自己手中创造的文化遗存, 却“正像我们 曾经不文明地对待文物古迹和历史文化街区一样, 今天又 正在迅速毁掉工业社会时代留下的文化遗产, ${ }^{\text {[1] }}$ 。加速实施

本文为国家社科基金项目《非物质文化遗产档案资源建设“群体智慧模式”研究》（项目批号：13BTQ060）成果之一。 
“退二进三”和“退城进园”战略, 对汽车工业旧址和厂房进 行关、停、并、转和全部拆除, 随后再改变土地利用性质 开展房地产开发已成为流行的城建运作模式。

这种不加区分地拆除, 不仅将导致十堰汽车工业遗产 的快速消亡, 使十堰也逐渐失去车城特色, 而且还将导致 我国工业文明初期的见证和记忆永远从人们的视线里消 失, 可见, 为了有限的商业利益而将优秀工业遗产拆除和 损毁是一项极其短视的行为。

\section{2 价值认识滞后}

“工业遗产通常被人们厌恶并与污染或沉痛的回忆联 系在一起”[2], 因为“它们创造的景观看起来像自然灾害或 历史失败的象征, 所以它们现在被列为迅速重点拆除的对 象” 面对各种类型的十堰汽车工业遗产, 不少人认为它们 只是生产加工和劳动就业的场所, 而被废弃或即将停产的 工业场所更是代表着过时和落后, 更有一些决策者认为被 淘汰的汽车厂房和生产系统是城市发展的废弃物, 既没有 漂亮的外观形象, 又曾有过噪音、废气、粉尘等污染, 是 十堰城市发展和形象塑造的包袱和障碍, 应将它们彻底清 理, 代之以新的高附加值项目。

可见, 认识的局限性导致了十堰市汽车工业遗产所蕴 含的历史、社会、科学、经济和审美等价值长期被忽略。 对有着辉煌工业传统的十堰市而言, 由于汽车工业遗产认 识局限带来的遗产损失正在不断加速, 这势必引发城市文 化断层的加剧, 进而对城市肌理和个性特征带来不可挽回 的损害。

\section{3 保护制度缺位}

尽管近年来我国工业遗产的保护已逐步受到多方重 视, 但受法律保护的工业遗产项目仅占应纳入保护范畴内 容的很小一部分, 同时也只有上海、天津、长春、武汉等 少数几个城市启动了城市工业遗产普查认定和保护规划制 定工作, 而大多数传统工业城市尚未将工业遗产保护纳入 文化遗产制度化保护的范畴。

就十堰市域而言, 其汽车工业遗产保护制度缺位主要 体现在法律滞后和法规缺失两方面。我国虽已颁布实行了 《非物质文化遗产保护法》、《中华人民共和国文物保护 法》, 以及知识产权法律体系等内容作为工业遗产保护工 作的参照标准, 但鉴于工业遗产的特殊性, 这些法律难以 对其进行清晰的界定、定位和规范。同时, 十堰市也未就 域内汽车工业遗产制定相应的地方性保护法规和保障政 策, 导致十堰汽车工业遗产保护既缺乏专门制度和规范方 法, 也缺乏唯一的保护主体、清晰的归属关系和明确的管 理责权。

\section{4 公众宣传淡薄}

“一些国家和地区的成功经验显示, 要想获得所期望的 公众支持, 就要使人们分享对工业遗产认定、记录和研究 方面的知识和兴趣, 因此, 宣传和教育非常必要”, ${ }^{[4]}$ 。工业 遗产清晰地记载各个历史时期工业企业的社会责任, 以及 在全球经济一体化背景下中国工业发展的历史进程和普通 劳动群众难以忘怀的人生旅程, 这些交融在一起的复杂认 同, 构成了一个城市社会认同感和归属感的基础, 对市民 心理将产生不可忽视的社会影响。

十堰市汽车工业历史悠久、积淀丰富, 长期以来在经 济发展、城市建设、生活水平、人员就业等多方面对城市 产生深刻而长远的影响, 已经成为十堰市民内心中的形象 载体和核心感召。面对丰厚的汽车工业遗产资源, 十堰市 仅有一所以东风“二汽”发展史为主要内容、归口东风汽车 有限公司管理的小型汽车专题展馆, 市内再无对汽车工业 遗产、汽车产业文化等元素进行有效展现的载体, 使公众 无法在第一时间感受到十堰车城的精神风貌。同时, 对大 量富余的汽车工业人力资源, 如离退休汽车工程师、退休 汽车产业工人、汽车文化志愿者等都未有效利用, 无法实 现十堰市汽车工业遗产进行免费宣传和广泛监督, 拉大了 城市居民与工业遗产之间的距离, 增大了十堰市汽车工业 遗产保护与利用的难度。

\section{3. 汽车工业遗产保护的基本原则}

\section{1 原真性保护原则}

“原真性是其形成时的外在环境与价值主体的真实状 况, 及其沿袭过程中未经人为干涉的环境与价值主体的自 然状态”, [6]。根据《奈良文件》指出的“有关文化遗产价值 及相关信息源可信性的一切判断, 在不同文化之间可能是 不同的, 甚至在同一文化内, 也可能不同。因此, 不可能

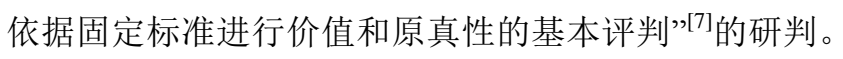

以法国为例, 在对工业遗产进行改造时, 一个重要的 原则是不影响遗产建筑的结构, 后来的改造添加物可以拆 除。体现了“工业遗产的改建再利用, 首先要思考旧空间与 新功能之间的关系, 在再利用过程中, 原有的部分、修复 的部分、新建的部分各自明确, 不应尝试混为一体” 的原 真性保护原则。可见, 在十堰汽车工业遗产保护过程中, 应“在明确价值的前提下, 确定保护的工业遗产虽然可以进 行再利用的开发, 明确区分划定保护范围, 以及需要区分 对象的“价值承载”与 一一般对象”之间的界限” ${ }^{[8]}$ 。 


\section{2 整体性保护原则}

《实施世界遗产公约的操作指南》的第9条、第30条规 定“文化遗产必须要有突出的普遍价值, 同时历史中心和历 史地区只有在大量具有纪念意义的古代建筑物、能直接显 示一座含有特别价值的城镇的特点时, 才能被列入名录。 不鼓励对各自代表城市结构已无迹可寻的城镇的几个单独

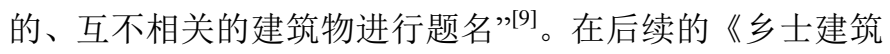
遗产宪章》、《下塔吉尔宪章》中还具体定义了历史时间、 地域特征、遗产特征、空间联系、功能发展均是完整性的 关键要素, 综合上述内容可知, 工业遗产的完整性主要指 工业遗产需要在物质结构、景观意向、社会功能三方面进 行有序保护与完整保留。

十堰市汽车工业遗产的整体保护有赖于遗产特征要素 之间完整关系的保存, 它们不仅包括各种设施设备、交通 体系、加工装置等要素与遗产之间的关系, 还包括了生活 区与生产区、服务区与流通区等区域同遗产之间的联系, 如果这种联系被破坏和割裂, 必将削弱十堰汽车工业遗产 的完整性。同时, 整体性保护原则还包括物质遗产与非物 质遗产的共同叠加与保护传承, 汽车工业遗产所形成的地 貌特征和工业建筑, 以及相关的辅助关联设施都是完整城 市景观的一部分, 完整的十堰汽车工业遗产体系不仅承担 了重要的教育意义和纪念意义, 还将继续承载着凝集十堰 人心、推动车城发展的社会功能, 这些曾在经济发展、经 营管理、解决就业等方面都具有突出贡献的工业遗产将永 远留在十堰人的生产生活、社会交往和思维范式中, 不断 体现汽车工业遗产巨大的社会价值和心理价值。

\section{3 活态性保护原则}

“文以物传, 物以文彰”既是城市工业遗产保护的基本 原则, 也是城市工业遗产的保护与再利用的互动发展目标, 其“文”为城市工业遗产需要保护的历史文化、社会、技术、 美学价值, 其“物”为城市工业遗产需要再利用的经济价 值, ${ }^{100}$ 。相对于博物馆式的静态保护, 工业遗产的活态性保 护是基于“保护为主, 抢救第一，合理利用，加强管理”的 文保方针, 利用工业遗产的物理形态, 结合城市的文脉内 涵, 采用多种利用举措让工业遗产重新融入现代社会生活, 推动保护与利用的良性循环, 实现工业遗产传承文化、融 入社会、服务公众的最终目的。

对十堰市汽车工业遗产而言, 应重视工业遗产所蕴含 的巨大历史价值和深厚的开发潜力, 将保护与利用汽车工 业遗产上升到全市战略层面, 把汽车工业遗产的保护与利 用统筹兼顾到各类城市规划之中。并从实际出发, 根据十 堰市文化资源和自身特点, 针对不同等级的汽车工业遗产,
提出相应的保护和利用措施和分期行动方案, 推动十堰市 汽车工业遗产融入社会、回归大众的历史进程, 同时获得 巨大的生态效益、社会效益和经济效益。

\section{4. 十堰市汽车工业遗产保护的实施对策}

\section{1 开展汽车工业遗产抢救性保护}

为了对十堰市汽车工业遗产进行及时抢救和有效保 护, 是现阶段全市汽车工业遗产保护的首要工作。在执行 过程中, 必须分清轻重缓急, 采取有力措施进行快速干预 和有效保护。

第一, 对现状进行管控。对已作为文物保护和工业遗 产登陆的汽车工业遗产, 市规划主管部门应按程序上报市 政府, 公布为历史建筑或工业历史街区, 按国家《名城名 镇名村保护条例》中有关历史建筑和历史街区的规定予以 保护。工业历史街区范围内构成整体风貌的重要建筑如需 改造更新, 不应采用拆除重建的简单方式。对历史价值较 高的工业遗产, 市文物主管部门应按程序列为文物保护单 位, 按照文物保护法的有关规定保护。

第二, 对企业进行引导。对于已搬迁原址, 但设施尚 未完全拆除的工业企业, 要立即采取紧急措施, 责令有关 开发企业对尚未拆除的工业遗产立即加以保护; 对于正在 搬迁的工业企业, 应尽快对其所属汽车工业遗产进行评估 登录, 划定保护范围。当原厂址土地和旧厂房出让时, 及 时将汽车工业遗产的保护计划纳入全市范畴; 对于确因工 程建设需要而需动迁的汽车工业遗产, 应尽快采取措施, 或整体记录、或收归馆藏、或异地重建; 对于不需搬迁的 工业企业, 其老设备、老厂房仍在使用的, 应敦促企业将 其所辖汽车工业遗产及时、全面地登录“十堰市汽车工业遗 产保护名录”; 对于已破产或停产的工业企业, 如其所辖汽 车工业遗产尚未得到处置的, 要立即划定保护范围、纳入 保护利用规划, 并尽快组织实施。

\section{2 推动汽车工业遗产规范化进程}

推动十堰汽车工业遗产规范化进程, 主要是建立健全 汽车工业遗产保护与利用的有关法规和制度, 实现对十堰 市保护汽车工业遗产的根本保障,

第一, 制定遗产保护制度。应根据《中华人民共和国 文物保护法》、《中华人民共和国非物质文化遗产保护法》、 《文物保护法实施条例》、《历史文化名城名镇名村保护 条例》等法规和国家各部委公布的近 40 项文保方面的部门 规章, 结合十堰市实际情况尽快制定《十堰市汽车工业遗 产登录制度》、《十堰市市工业遗产保护条例》、《十堰 
市工业遗产管理制度》和《十堰市工业遗产利用制度》等 地方性工业遗产保护法规。

第二, 制定遗产保护规划。尽快制定并落实《十堰汽 车工业遗产保护利用规划》, 在内容中充分体现“发展和保 护的关系, 把保持城市原有的特色和展示城市发展前景有 机地结合起来, 真正使城市规划经得起实践和历史的检 验, ”[1]的指导精神, 并与《十堰市 “十二五”城市发展总体规 划》相对接, 实现全市范围的统一领导和整体部署。

第三，制定遗产保护政策。制定和实施优惠政策以调 动企业保护工业遗产的积极性, 是十堰市加强汽车工业遗 产保护的重要环节。按“谁拥有、谁保护、谁利用、谁受益” 的原则, 清楚界定汽车工业遗产的归属关系、管理关系和 监督关系, 同时制定遗产占用土地补偿政策、遗产建筑空 间利用政策、遗产改造投资免税政策、遗产利用收益税收 减免政策等一系列优惠政策, 充分调动汽车工业企业保护 遗产的积极性。

\section{3 实现汽车工业遗产生产性保护}

生产性保护是工业遗产活态性保护的重要体现, 也是 推动工业遗产重新融入社会生活的主要手段。十堰市汽车 工业遗产具有内容多样、层次丰富、文化深厚、特征明显 等特点, 应根据实际情况分别采用多种生产性保护举措, 实现全市汽车工业遗产的科学利用。

第一, 发展汽车工业遗产旅游。利用十堰汽车工业遗 产禀赋, 突破当前散点布局的利用模式, 以“中国汽车工业 史”为主题打造“十堰——襄柇——武当山镇”的汽车工业 遗产旅游线, 重点开发特色汽车工业旅游项目和汽车体验 活动, 实现十堰汽车工业遗产同武当山世界文化遗产的有 效对接, 增强十堰城市旅游吸引力, 加快老工业的转型和 升级。

第二, 实现遗产综合性应用。根据具体条件, 可以将 汽车工业遗产改造升级为商业设施、办公设施、高档公寓 区等项目。其中, 利用工业建筑的空间优势和集群优势实 现特色片区的整体利用, 吸引创意人才及产业聚集并构筑 城市创意产业园, 是国内老工业基地转型升级的重要途径 之一。《十堰市国民经济和社会发展第十二个五年规划纲 要》提出, “要将十堰打造成为以“三区一中心为核心内容 的区域性中心城市, 即: 国际知名生态文化旅游区、国家 级汽车产业集聚区、国家级生态经济示范区和区域性现代 服务中心” ${ }^{[12]}$ 。以此为契机, 十堰市汽车工业遗产可按照不 同主题和产业定位, 因地制宜地重新包装成以文化演艺类、 创意设计类、传播媒体类为主要内容, 包括文化艺术、新 闻出版、广播、电视、电影、软件设计、网络及计算机服 务、广告会展、艺术品交易、设计服务、旅游休闲娱乐和
其他辅助服务等项目在内的创业产业, 助力十堰市“退二进 三”历史发展进程。

第三, 设置工业遗产博览场馆。各类汽车工业主题博 物馆是十堰重要文化设施, 也是展现十堰工业特色和历史 价值的窗口, 更是加强爱国主义教育的重要基地。现阶段, 十堰市虽已有一所“汽车历史展览馆”, 但拘于内容单薄、 场地狭小、多头管理等原因, 已难以满足日益增长的社会 文化需求。未来应重点考虑将市内一处大型汽车工业遗产 地改扩建为“十堰汽车工业博物馆”, 结合其他汽车工业遗 产所设置的主题专业汽车工业博物馆, 形成以“体现中国工 业历史, 充分展示汽车文化, 体验形式丰富多样, 整体覆 盖十堰全域”的汽车工业遗产博览体系, 向全世界充分展示 十堰的文化底蕴和丰富内涵。

第四, 打造汽车主题景观体系。作为中国车城的湖北 十堰, 在城市风貌和地标特征上还尚未充分体现其深厚汽 车产业历史和丰富的汽车文化内涵, 使十堰丧失了挖掘产 业文化、彰显自身特点、推动三产发展的重要机会。未来, 十堰市应立足于充分保护和挖掘自身汽车文化遗产, 以汽 车产业文化为主题, 从打造全域汽车主题景观体系的高度, 推动十堰市成为全国第一个“全域工业遗产保护区”和“全 域汽车文化体验区”, 将文化保护、产业发展、都市建设、 文化体验和市民休闲有机结合, 形成并凸显十堰市独特的 城市特征。

第五, 启动“五个一”遗产保护工程。为推动十堰市对 域内汽车工业遗产进行整体保护和有效利用, 提出启动“五 个一”遗产保护工程作为全市工作抓手, 即随厂保护一批, 申报文物一批, 转型利用一批, 馆藏保护一批, 立碑公示 一批。

随厂保护一批指仍处于正常运营阶段一些老企业, 其 所属老设备、厂史档案等汽车工业遗存可随厂迁移。如二 汽各分厂的企业厂史陈列室、军品陈列馆和尚不够文物的 老设备等项目, 均可随厂搬迁加以保护; 申报文物保一批 指具有文物价值的汽车工业遗产区域、建筑和设备, 应按 程序申报文物, 并依法纳入文物保护范畴; 转型利用一批 指不用刻意改造就可以直接利用的汽车工业遗产, 应在保 持其原有风格和体量的基础上加以保护和利用, 实现汽车 工业遗产的社会价值和经济价值, 避免城市建设的大拆大 建; 馆藏保护一批指在我国汽车工业发展史上有价值的设 施设备、工业产品、技术代表等内容, 应建立博物馆集中 收藏保护; 立碑公示一批指因搬迁、停产或改建等原因, 原有汽车工业遗产区域、建筑或设施已荡然无存的地域, 应在遗址的适当位置立碑标识, 以便体现遗产的完整性并 实现文化传承。 
工业遗产是我国文化遗产体系的重要组成部分, 对工 业遗产的全面保护标志着我国文化遗产保护体系的正不断 走向完善和深入, 文化遗产保护意识与关注热点也逐步由 古代走向现代、从馆藏走向生活、从保护走向利用。十堰 市汽车工业遗产作为十堰市重要的发展见证和城市肌理, 具有很高的历史价值、文化价值、社会价值和利用价值, 尽快对全市汽车工业遗产进行甄别与保护, 不仅是对历史 负责、对后代负责的首要举措, 而且还是延续郧阳千年文 脉的必要工作, 同时更是盘活存量资产、避免重复劳动、 激活文化价值的重要抓手。

\section{参考文献(References)}

[1] San Ji Xiang. Focus on the New type culture heritage. China Cultural Heritage, 2006(4): 35.

[2] Li Xuedong, Li Xibin, Sun Aiqin. Three stage design theory of management organization and management research. Dalian University of Technology Press. 436-445.

[3] UNESCO. Convention Concerning the Protection of the World Cultural and Natural Heritage.[2013-4-28]. http://whc.unesco.org/en/conventiontext/

[4] San Ji Xiang. The protect measures of industrial heritage. China Ancient City, 2011(4): 6.
[5] UNESCO. Convention Concerning the Protection of the World Cultural and Natural Heritage.[2013-4-28]. http://whc.unesco.org/en/conventiontext/

[6] UNESCO. The Nara Document on Authenticity 1994. [2012-11-20]. http://www.unesco.org/

[7] Kou Huai Yun. The value research of industrial heritage. Shanghai:Fudan University,2007.

[8] Chefif Khaznadar. Traditional knowledge and Intellectual Property.Gardozo Joumal of International and Comparative Law. Summer. 2003

[9] Unesco. Cultrual industries. New Yourk: UNESCO. http://www.unesco.org/bpi/pdf/memobpi25_culturalindustries_ en.pdf(2011.11)

[10] Hesselink N. Intangible cultural properties as icons of identity. Perspectives on Korean music, vol 1. AFRICAN STUDIES-UNIVERSITY OF LONDON, 2007,70(2): 449-451 .

[11] Qi Xiao Din. The direction way of Chong Qin, China by chairman Hu. Chong Qin News, 2007-3-9(1).

[12] The government of Shi Yan. The develop plan of Shi Yan(2010-2015). Shi Yan Daily,2011-1-23(2). 